\author{
FINAL REPORT \\ U.S. Department of Energy
}

\title{
OPTICALLY-BASED ARRAY SENSORS FOR SELECTIVE IN SITU ANALYSIS OF TANK WASTE
}

\author{
Principal Investigator: Gilbert M. Brown \\ Institution: Oak Ridge National Laboratory
}

Co-Principal Investigators: Reza Dabestani and Peter V. Bonnesen

Institution: Oak Ridge National Laboratory

Co-Principal Investigator: David R. Walt

Institution: Tufts University

Collaborators: Hai Feng Ji and R. L. Hettick Institution: Oak Ridge National Laboratory

Collaborator: Caroline L. Schauer, Institution: Tufts University

Project Number: EMSP No. 60217

Grant Number: TTP No. OR17SP23 3THN

Project Duration: September 1, 1997 to March 31, 2001 


\section{Table of Contents}

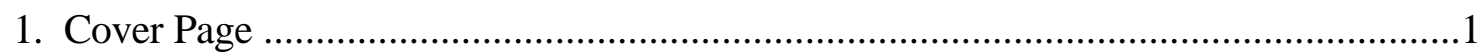

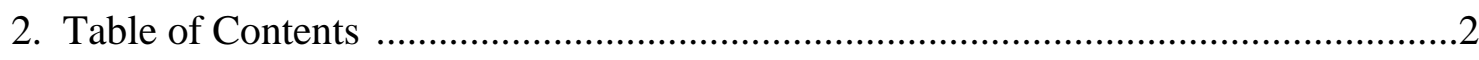

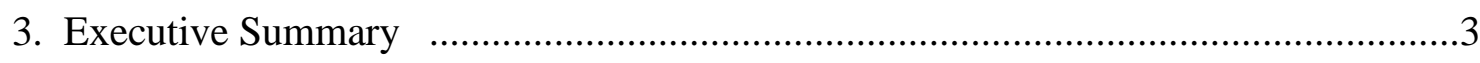

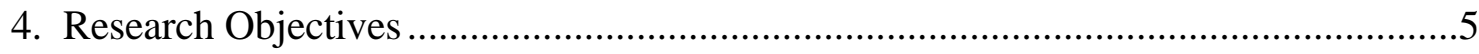

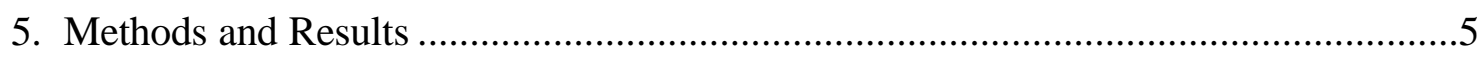

6. Relevance, Impact, and Technology Transfer. ...............................................19

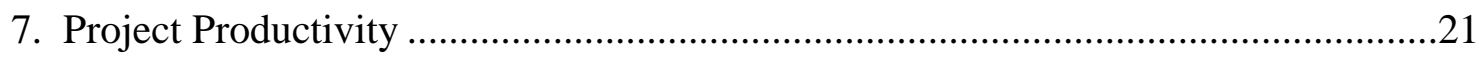

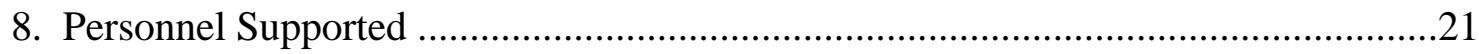

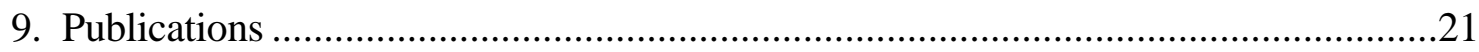

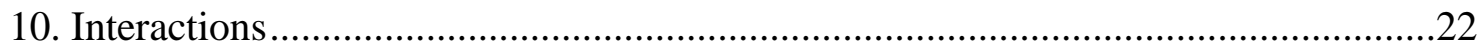

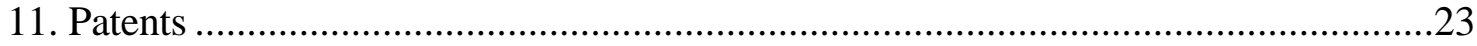

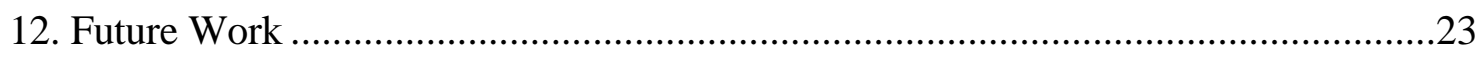

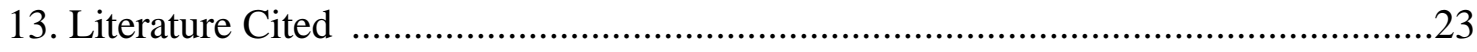




\section{Executive Summary}

The objective of this research program is to conduct the fundamental research necessary to develop an array of chemically selective sensors, based on highly selective molecular recognition agents and highly sensitive fluorescence techniques, that can be coupled to fiber optics for remote analytical applications. These sensors will be of great value to DOE for the safe and cost-effective in situ characterization of high level waste tanks and other applications where remote sensing will prevent workers from being exposed to chemicals or radiation. We are developing a fluorophore-selective ligand combination needed for a $\mathrm{Cs}+$ selective fluorescence sensor. Calix[4]bis-crown-6-ethers in the 1,3-alternate conformation have been shown to possess a high degree of selectivity for cesium over sodium and moderate selectivity for cesium over potassium. Several systems involving the preparation of a new class of calixarene-based ionophores having attached fluorescent probe molecules were demonstrated. Cyanoanthracene attached to the benzyl group of a benzo crown was prepared as the first generation of a cesium selective optical sensor. The fluorescence of the 9-cyanoanthracene is quenched by the benzo moiety of a crown ether owing to a Photoinduced Electron Transfer (PET) process. It has been shown that binding of the oxygen electron pairs of the benzo moiety upon metal ion complexation partially suppresses the PET process, allowing the fluorescence of the cyanoanthracene to increase. The synthesis of a 1,3-alternate di-deoxygenated calix[4]arene-(9cyano-10-anthrylmethyl)-benzocrown-6 as the second generation cesium selective fluorescent probe has been accomplished. This probe shows a 54-fold fluorescence enhancement response upon cesium complexation, which is the best result we have achieved to date. The observed selectivity ratios $(\mathrm{Na} / \mathrm{Cs}$ and $\mathrm{K} / \mathrm{Cs})$ are consistent with data reported for other 1,3-alternate calix[4]dialkoxy-crown-6 derivatives.

Preliminary work was carried out to translate these solution results to organic films with the goal of translating to chemically modified beads. Polymer inclusion membranes (PIMs) based on celulose triacetate and trihexylphosphate or polyvinylchloride and octanol were prepared and investigated. Only modest enhancements in emission were noted, and the rigid confirmation of the receptor-fluorophore combination within the PIM may be at fault.

In a new concept for utilization of these sensor elements, the application to the development of logic devices has been pursued. The high selectivity exhibited by calix[4]crown6 ethers towards the complexation of alkali metal ions has been exploited to synthesize a supramolecular fluorescent recognition agent capable of detecting both potassium and cesium ions in solution by PET. The newly synthesized probe also behaves as an integrated logic gate combining an OR and a NAND gate for signal transduction. This is the first example of an 
integrated molecular logic device with feed back to the input of one logic element from the output of another. 


\section{Research Objectives}

The objective of this research program is to conduct the fundamental research necessary to develop an array of chemically-selective sensors, based on highly selective molecular recognition agents and highly sensitive fluorescence techniques, that can be coupled to fiber optics for remote analytical applications. The ability to detect and measure specific chemicals and radionuclides directly inside a high level waste tank using a remote sensing device could result in considerable benefits with regard to both cost savings and safety issues. An array of fiber optic sensors will be of great value to DOE for the safe and cost-effective in situ characterization of high level waste tanks and other applications where remote sensing will prevent workers from being exposed to chemicals or radiation. In this approach to the design of sensors, agents for selective molecular recognition such as crown ethers are immobilized in an organic polymer matrix that mimics the organic medium in an aqueous-nonaqueous extraction system. The matrix is attached to an optical fiber for remote detection of metal complexation by photonics measurements.

Selection of the complexation agent and solvent are derived from our knowledge of metal ion specificity in the analogous aqueous-non-aqueous solvent-extraction chemistry. We additionally utilize our knowledge of synergistic effects for enhancing both the selectivity and the loading in the solvent extraction of alkali metals from tank waste by proper design of the polymeric matrix and by incorporating appropriate co-extractants into the matrix. The objective is to maximize the selectivity for and the degree of binding (loading) of the desired metal ion by the sensor's solid matrix while maintaining stability in the highly alkaline environment of tank waste. This novel approach to the design of photonics-based sensors should result in increased chemical selectivity, which at present is a fundamental limitation of many chemical sensor devices. When fully implemented, this scheme will utilize an array of sensor sites, each with optimized selectivity for one of the components in the analyte.

\section{Methods and Results}

This project focused on the underlying fundamental principles of sensor technology that are specifically applicable to the problems of designing an array of fiber optic-based sensors for use in high-level waste tanks or monitoring waste streams in processing applications. Inexpensive direct-reading, chemical sensors for these applications may have the required sensitivity, but they often lack the required selectivity or the tolerance for the harsh media typical of DOE applications (tank waste). Many of the problems with selective chemical sensors can be eliminated by combining well designed molecular recognition agents with a supporting matrix that can withstand the harsh environment and that can enhance the selectivity for the desired analyte. It is important to recognize that, although desirable, it is not necessary for the molecular 
recognition agents to be absolutely selective. With an array of sensors, each with some crossreactivity, it is possible to train the sensor to recognize cross reactivity patterns and to extract the concentrations of individual analytes (metal ions) from the generated signal pattern. Neural network, principal components, or partial least squares analysis programs could be used to train the sensor array.

A chemical sensor device or system is composed of four main components: a receptor for the target molecule or class of molecules being sensed, a matrix with the dual task of immobilizing the receptor and enhancing the receptors selectivity, a method by which the sensing event can be converted into an energy form which can be measured and quantified (transduction), and a means by which the signals can be analyzed or interpreted. The refinement and integration of all of these components will be required for the development of a viable sensor. Our approach to the design of sensors will be to immobilize agents for selective molecular recognition, chosen from solvent extraction processes, in a matrix that mimics the organic medium in an aqueous-nonaqueous extraction. In solvent extraction experiments using cesium selective ionophores, the properties of the diluent can have a tremendous effect on the degree of loading of the ionophore with cesium ${ }^{1}$. While there is considerable precedent for incorporating metal-ion selective agents into solvent impregnated membranes ${ }^{2,3}$, the selection of the organic carrier solvent for the matrix, as well as the selection of co-extractants or other synergistic agents, can influence both the degree of complexation of the metal ion by the ionophore and the selectivity over other metal ions. In this manner, the matrix will enhance both the separation and the achievement of chemical selectivity.

The transduction part of the sensor will be based on coupling the separation/molecular recognition agents with a photonics-based detection scheme. Our approach is to utilize complexation of the separated species by an agent or ligand containing a fluorophore, where communication between the metal ion binding site and the fluorophore will signal the presence of a bound metal ion. Such compounds containing both a binding site in communication with a fluorophore are referred to as fluorescent chemosensors, and have been the focus of much research in recent years ${ }^{4}$ Our work has focused on the fluorescence turn-on mechanism. A fluorophore (such as 9-cyanoanthracene) is connected by a methylene linker arm to the benzene ring of a benzo-crown ether which functions as the metal cation receptor site. The lowest singlet excited state of 9-cyanoanthracene (fluorescent state) is a good electron acceptor and can be quenched by electron transfer from the 1,2-dialkoxybenzene group (good electron donor) of the crown ether in the absence of a metal ion. However when a metal cation is bound to the oxygen atoms of the crown ether, the presence of the positively charged center changes the thermodynamics of the quenching reaction (because the metal-coordinated 1,2-dialkoxybenzene is no longer such a good electron donor) allowing the anthracene moiety to fluoresce (turn on). 
The fluorescence turn on results from a decrease in the rate of photoinduced electron transfer (PET) reaction ${ }^{5}$ which can not compete with the rate of fluorescence. PET, in which an electron is transferred from the oxygen donor atoms to the excited anthracene, is a rapid reaction which competes with and quenches normal fluorescence from anthracene in the absence of a metal ion. Thus by binding the oxygen lone pairs through complexation with cesium, the fluorescence of the molecule is switched on.

The translation of proven solution-based selective chemical separations to a receptortransducer platform has been a challenge in sensor technology. In our approach, we have tested polymer inclusion membranes (PIMs) in which a thin matrix or membrane to contains the elements of the system responsible for separation and selectivity. The next step is to translate these results to more practical micron-sized chemically modified beads. The properties of the matrix containing the molecular recognition agent can influence the selectivity and the sensitivity of the sensor. Our general approach will rely on partitioning the analyte into the matrix containing the molecular recognition agent as part of the means of achieving selectivity. This approach is common in solvent extraction, and partitioning the analyte of choice to a different environment prior to bringing it in contact with the transducer element is expected to be successful.

However, translation of proven chemistry to a form suitable for sensor applications by attaching the fluorophore-complexation agent combination to a solid support may either diminish or enhance the performance when compared to the behavior in solution. Diminished sensing capability could be attributed to new constraints being placed on the chemical system by the rigidity of the support environment. For photoinduced electron transfer (PET)-based fluorophores, in which metal ion binding activates the fluorescence, surface attachment or embedding of the assembly in a matrix can lead to reduced conformational freedom and changes in electronic properties. These two new sources of potential constraints on the chemical sensing system could change either the kinetics or the thermodynamics of the electron transfer quenching reaction.

A sensing device of the sort we envision with an organic matrix in an aqueous medium can be considered as a biphasic liquid system similar to the classical liquid-liquid extraction system. In both cases, a common interface separates the aqueous and organic phases, and ionic species of interest are distributed between these phases. Distribution of a solute between two immiscible liquids upon their contact is an equilibrium process which depends on the partitioning of the metal ion, accompanied by a counterion, between phases, metal ion-ligand complex formation, and ion association in the organic phase. Comprehension of what type of coordination environment of the solute in each phase provides the most energetically stable state of metal ion is the basis for the prediction of its distribution behavior. While the properties of 
the aqueous phase with respect to coordination of metal ion are rather invariant, organic solvent and macrocyclic receptor can be chosen to satisfy separation needs. Extractability of the metal ion greatly depends on the magnitude of the complex formation constant in the organic phase. The enhancement of the complexation stability constant is desired for most separations, and this is the target of the proper receptor design. The organic solvent influences the complex formation constant through solvation of the metal ion and the ligand. It is commonly recognized that the stability of the complex increases when the cation is poorly solvated. This implies that solvents of low dielectric constant, large molar volume, and low hydrogen bond acceptance index $\beta$ favor complex formation. Solvents with these properties are normally chosen for practical separations. However, transfer of the ion from aqueous to non-polar organic phase takes the majority of the energy released upon complexation, and overall result is often low separation efficiency. Thus, in many cases polar solvents are preferred. Since crown ethers possess electron donating capabilities, they readily interact with different solvents. To this end, the solvent effects not only the complexing properties of the ligand but also the fluorescence properties of reporter groups. It is important to note that, in many cases, selectivity of cation binding by a macrocyclic receptor is altered when homogeneous liquid system is replaced by biphasic separation system. Nonetheless, knowledge of the homogeneous association constants is necessary for the initial prediction of the separation efficiency, selectivity, and optical activity. Thus, investigation of the complexation behavior in the homogeneous medium is of primary importance in the design of an effective sensor, and this has been the focus of the majority of the work conducted in this project.

Fiber Optic Sensors. Individual optical fibers can be converted into sensor elements by attaching the probe molecule in an appropriate matrix to the distal tip of the fiber. When light at an excitation wavelength is focused onto the proximal end of the fiber, the fluorescent label on the distal end or on the core becomes excited. Isotropically emitted light from the fluorophore is captured by the same fiber and sent back to the proximal end where a detection system separates the excitation light signal from the emitted signal. However we would like to develop arrays of sensor elements. Single strands of transparent materials such as glass, plastic, or fused silica can propagate light over long distances with minimal attenuation. Since light undergoes thousands of reflections per meter as it is guided down the length of the fiber, the position at which an individual ray exits the fiber will not correspond to the position at which it entered the fiber. ${ }^{6,7}$ Images cannot be carried over conventional optical fibers because the light signals become mixed and spatial resolution is not preserved. Imaging optical fibers have been created that contain an array of thousands of densely packed individual optical fibers fused into a coherent unitary bundle. ${ }^{8}$ These fibers are prepared by bundling larger optical fibers into a preform that is melted and pulled by a rotating drum to form the resulting fiber "thread", which has an identical structure and aspect ratio to the initial preform but is reduced in diameter. Typical imaging arrays 
contain between 5000 and 50,000 individual fibers, each 3 to $7 \mu \mathrm{m}$ in diameter, creating a total array diameter of 300 to $1000 \mu \mathrm{m}$. Each fiber carries its own light signal; consequently, such arrays can be used to build up images with a pixel-by-pixel image reconstruction similar to that of an insect's compound eye.

Recently, Walt and coworkers have used coherent imaging fibers to make fiber-optic chemical sensors, in which sensors are made with spatially-discrete sensing sites for multianalyte determinations. These multi element or array sensors have been applied to a number of topics including such diverse topics as vapor recognition in an artificial nose $\mathrm{e}^{9,10,11,12}$ and DNA sequence analysis ${ }^{13,14,15,16,17}$.

The ideal chemical sensor measures the in situ concentration of analyte continuously, reversibly, inexpensively, and rapidly. In most situations where measurements are

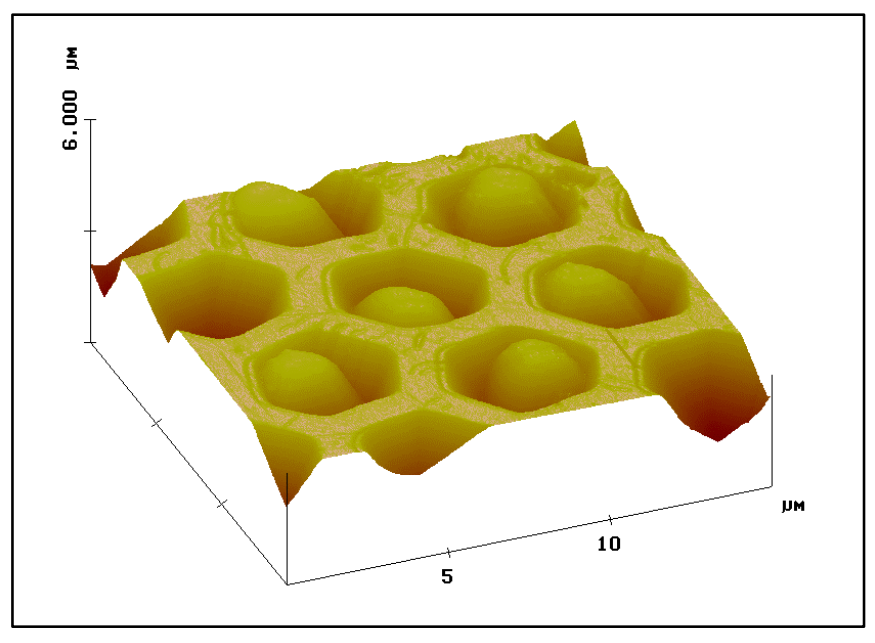
taken, it is important to measure several parameters simultaneously. One of the benefits accrued by using an imaging fiber in the fabrication of a multianalyte fiber-optic chemical sensor is the ability to selectively address the separate optical pathways of the imaging fiber during the indicator immobilization procedure. Walt and coworkers have developed randomly encoded array sensors based on microwells etched on the tip of an imaging fiber optic. ${ }^{18}$ The distal end of a fiber's core can be selectively etched relative to the cladding when exposed to various chemical etching agents such as hydrofluoric acid. Wells of different depths are created depending on the strength of the etching agent and the exposure time. ${ }^{19}$ The figure shows a scanning force micrograph image of the etched surface of an optical imaging fiber. In this image, a section of an array containing wells about $2 \mu \mathrm{m}$ deep is shown. At the bottom of the wells are the distal ends of the fiber that compose the array. Thus, each well is optically wired so that it can be tested individually. Latex or silica beads can be loaded into the wells either by dipping the etched fiber into a bead-containing solution or by applying a small aliquot of bead solution directly to the fiber tip. Upon drying, the beads are held firmly in the wells. (See AFM image.) An atomic force microscope image of the surface is shown in the figure. Polymer bead microspheres with the molecular recognition agent are prepared and then applied to an optic fiber that has been etched. The beads position themselves in the microwells when the sizes are well matched. Microspheres having different molecular recognition agents for probing each ion or physical 
property are prepared. By changing the fluorescent groups as the chemistry is changed will allow molecular recognition agents with different selectivities to be encoded separately.

Using a charge coupled device, the fluorescence from each of the different sensing regions immobilized on the imaging fiber can be spatially resolved. The creation of spatially discrete sensing sites on a single optical sensor solves many of the problems associated with designing multianalyte optical sensors such as spectral overlap of multiple indicators and the need to use individual optical fibers for each analyte

In this project, these optical imaging fibers will be employed as a generic architecture for immobilizing the chemically selective molecular recognition agents in a matrix designed to enhance the selectivity for ion binding. The strategy for obtaining selective measurements from an optical sensor array will explore a new sensing paradigm. First, fluorescent ion-sensitive compounds, each of which preferentially binds one of the constituents of tank waste- $\mathrm{Na}^{+}, \mathrm{K}^{+}$, $\mathrm{Cs}^{+}$, or $\mathrm{Sr}^{2+}$ - will be immobilized in different regions of the array, identifiable by the spectroscopic signature of the fluor. Because each compound possesses some cross reactivity for the other ions, interferences would be a problem if the sensor relied exclusively on complexation to one compound. By immobilizing a number of receptor compounds, we will look simultaneously at the fluorescence response pattern due to metal complexation. Using pattern recognition algorithms (e.g. Principal Components Analysis, Partial Least Squares) we should be able to deconvolute the precise concentrations of each metal ion from the array's response pattern. This approach is similar to one used by us to detect organic vapor mixtures with an array of cross-reactive fluorescent polymers. ${ }^{20,21}$

Imaging fiber arrays possess the same advantage for environmental monitoring and sensing applications as conventional single core fibers. The low attenuation allows the fibers to be used remotely, often hundreds of meters from the instrument to which they are connected. The small size of the fibers minimizes the well diameter needed for down-hole measurements or the penetration needed for in-tank monitoring. In addition, the optical basis for the measurements provides immunity toward electromagnetic interference. Finally, multiple sensors can be interfaced to the same instrument providing multiplexing capabilities if several sampling zones or monitoring sites are required, thereby leveraging the instrument capabilities.

Development of Fluorescent Turn-on Ligands. Calix[4]bis-crown-6-ethers in the 1,3alternate conformation ${ }^{22}$ have been shown to possess a high degree of selectivity for cesium over sodium (Cs/Na selectivity $\geq 10^{4}$ in selected diluents ), and moderate selectivity over potassium $\left(\mathrm{Cs} / \mathrm{K}\right.$ selectivity $\geq 10^{2}$ in selected diluents $\left.{ }^{1,23}\right)$. Ligands based on this and other crown ether ligands were chosen for investigation in this program. Because these calix crown ligands have such high selectivity for $\mathrm{Cs}^{+}$over other alkali metal ions, significant effort has been directed 
towards their use in the sensing, monitoring, and remediation of ${ }^{137} \mathrm{Cs}$, a fission product present in the wastes generated during the reprocessing of irradiated nuclear fuels. ${ }^{24}$ The need for sensitive cesium sensors has led to the study of modified calix[4]arene crown- 6 ethers as fluorescent cesium probes. 1,3-Calix[4] bis(9-cyano-10-anthrylmethyl)-o-benzocrown-6 (see structure in the figure) has been synthesized as a first generation cesium selective fluorescent probe, and its emission behavior in the presence of $\mathrm{Li}^{+}, \mathrm{Na}^{+}, \mathrm{K}^{+}$, and $\mathrm{Cs}^{+}$ions has been examined. This fluorophore was shown to be an effective fluorescence turn-on group, exhibiting a ten-fold increase in fluorescence when $\mathrm{Cs}^{+}$binds to the oxygens of the benzo crown moeity. This molecule was prepared by the synthetic route shown in the reaction scheme at the bottom of this page. The fluorescence of this bis crown system as a function of $\mathrm{Cs}^{+}$concentration shows two plateau regions, indicating both crown sites are being complexed. This is somewhat surprising in light of solvent extraction results with a highly lipophilic derivative of 1,3calix[4]arene bis(t-octylbenzylcrown-6) in 1,2-dichloroethane solvent ${ }^{25}$. In the later case the lower dielectric constant of the medium necessitates a higher concentrations of $\mathrm{Cs}^{+}$to promote complexation of the second ion. Measurements in a 1:1 $\mathrm{CH}_{3} \mathrm{OH}-\mathrm{CH}_{2} \mathrm{Cl}_{2}$ medium show that 1,3alternate calix[4]-bis-o-benzocrown-6 and 1,3-alternate dialkoxy calix[4]-o-benzocrown- 6 ethers bearing a cyanoanthracene fluorophore exhibit 8-12 fold fluorescence enhancement in the presence of cesium ion. ${ }^{26}$ The $\mathrm{K}_{\mathrm{CS}} / \mathrm{K}_{\mathrm{K}}$ and $\mathrm{K}_{\mathrm{CS}} / \mathrm{K}_{\mathrm{Rb}}$ of $13-38$ and of $1.3-2.5$, respectively, indicate that the observed selectivities are generally consistent with data reported for other 1,3alternate calix[4]-crown- 6 derivatives using UV absorption and potentiometric measurements. ${ }^{27}$

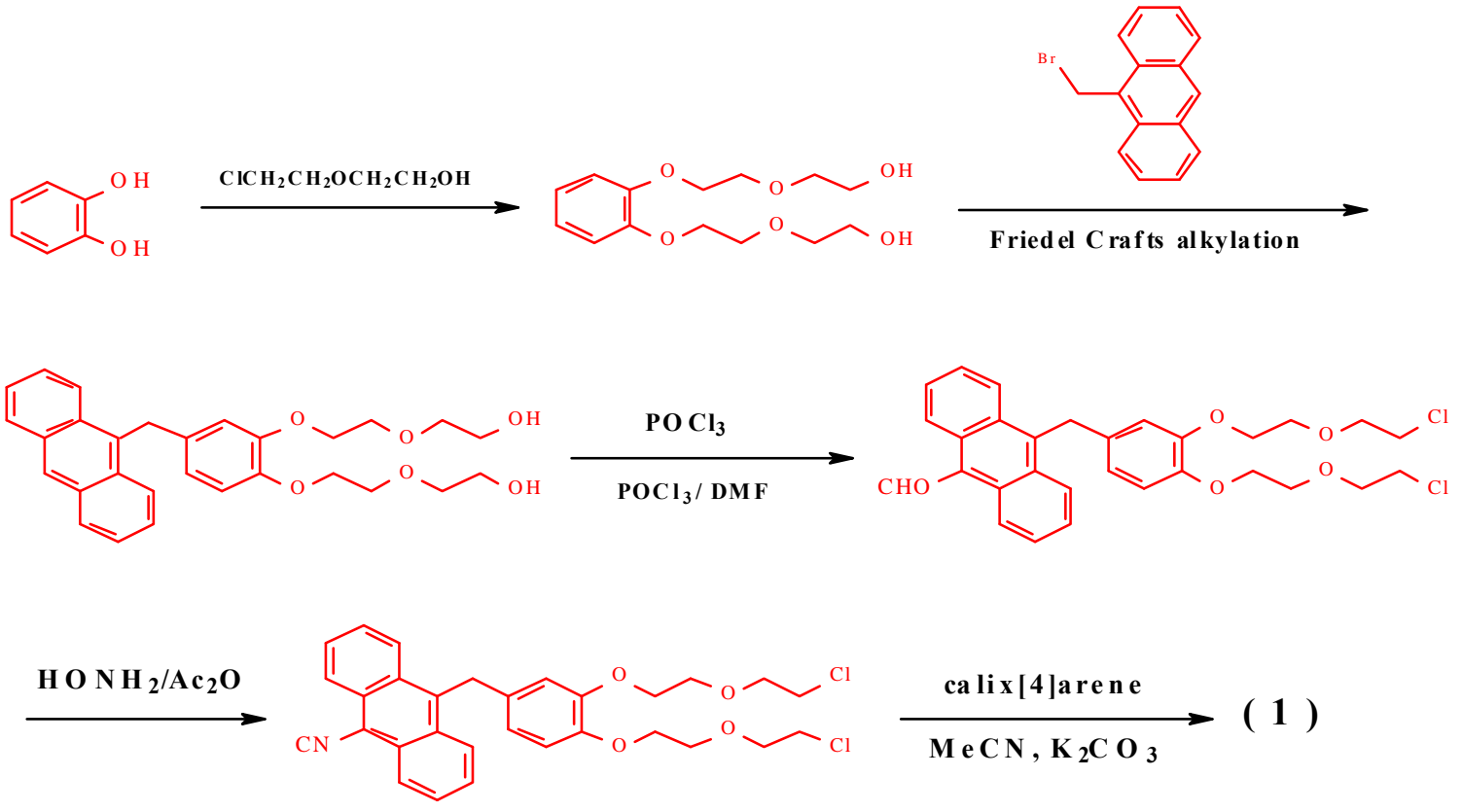



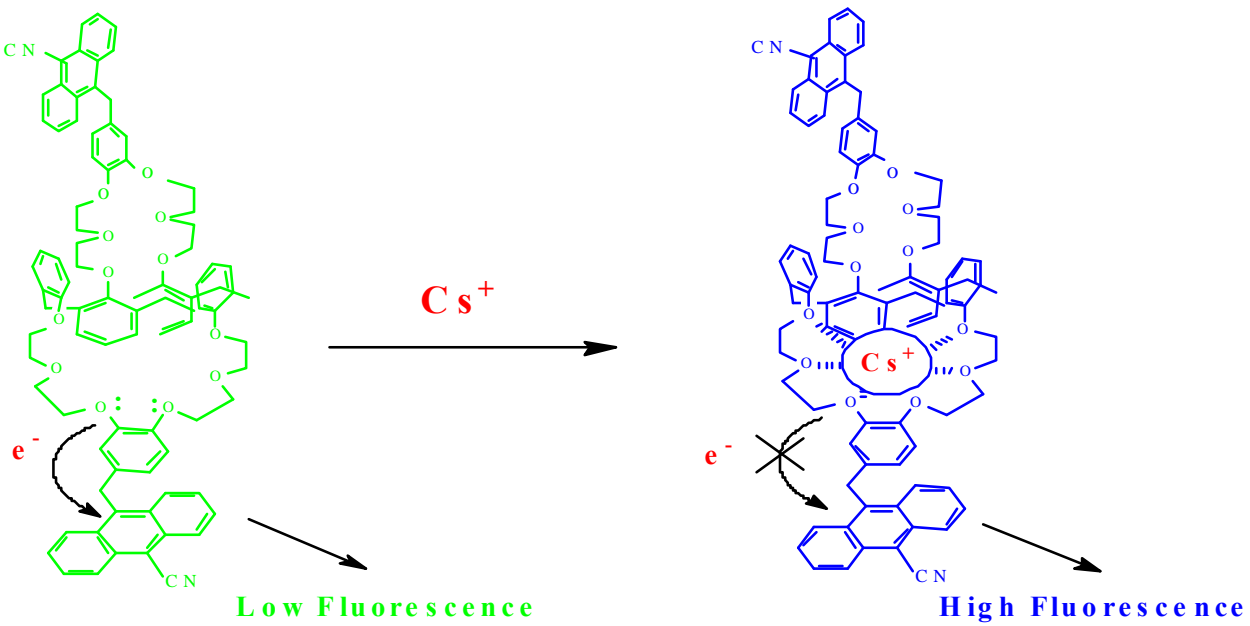

We have synthesized four derivatives of alkyl pyrene covalently bonded to aza-18crown- 6 at the nitrogen position, $\operatorname{Py}\left(\mathrm{CH}_{2}\right)_{\mathrm{n}},(\mathrm{n}=1-4)$, to study the effect of spacer length on the emission properties of pyrene fluorophore upon complexation of alkali metal ions by the crown moiety, in the absence of alkali metal ions, the parent molecule is weakly fluorescent because its emission is partially quenched by photoinduced electron transfer (PET) from nitrogen lone pairs to the excited singlet state of pyrene. Complexation of alkali metal ions (e.g. $\mathrm{K}^{+}$) by the crown moiety prevents the nitrogen lone pair from participating in PET and results in an enhancement in the observed emission from pyrene (fluorescent turn on). Because the PET effect could be exerted through bonds as well as space, its magnitude may show a dependence on chain length. We have examined the fluorescence behavior of these pyrene aza-crown ether derivatives in the presence of alkali metal ions to determine the magnitude of such an effect and its impact on the sensitivity of the fluorescent probe for detection purposes. Our results indicate that maximum efficiency for PET between the pyrene moiety and aza-crown ether is achieved when $\mathrm{n}$ is less than or equal to 3 .

Recently, it was reported ${ }^{17}$ that 1,3-alternate dideoxygenated calix[4]-crown- 6 ethers exhibit enhanced selectivity for cesium over potassium and rubidium compared with their 1,3alternate dialkoxy-calix[4] crown-6 derivatives. In an effort to take advantage of this higher cesium to potassium selectivity, we synthesized a new cesium selective probe. We have synthesized 1,3-alternate di-deoxygenated calix[4]arene-(9-cyano-10-anthrylmethyl)benzocrown-6 (2) and 1,3-alternate calix[4]arene-(9-cyano-10-anthrylmethyl)-benzocrown-6 (3) as second generation cesium selective fluorescent probes. (See structures on the next page) Probe (2) shows 54 fold fluorescence enhancement response upon cesium complexation while (3) exhibits only 8-fold enhancement. The selectivity ratios for (2) to complex cesium over potasium and rubidium $\left(\mathrm{K}_{\mathrm{CS}} / \mathrm{K}_{\mathrm{K}}\right.$ and $\left.\mathrm{K}_{\mathrm{CS}} / \mathrm{K}_{\mathrm{Rb}}\right)$ are about ten fold higher than those of (3) for the same ions. The observed selectivity ratios are consistent with data reported for other 1,3- 
alternate calix[4]dialkoxy-crown-6 derivatives. The selectivity ratios for this ligand to complex cesium over potassium and rubidium $\left(\mathrm{K}_{\mathrm{Cs}} / \mathrm{K}_{\mathrm{K}}\right.$ and $\left.\mathrm{K}_{\mathrm{CS}} / \mathrm{K}_{\mathrm{Rb}}\right)$ are about ten fold higher than the first generation ligand. The observed selectivity ratios are consistent with data reported for other 1,3-alternate calix[4]dialkoxy-crown- 6 derivatives. Our results suggest that these new calix-
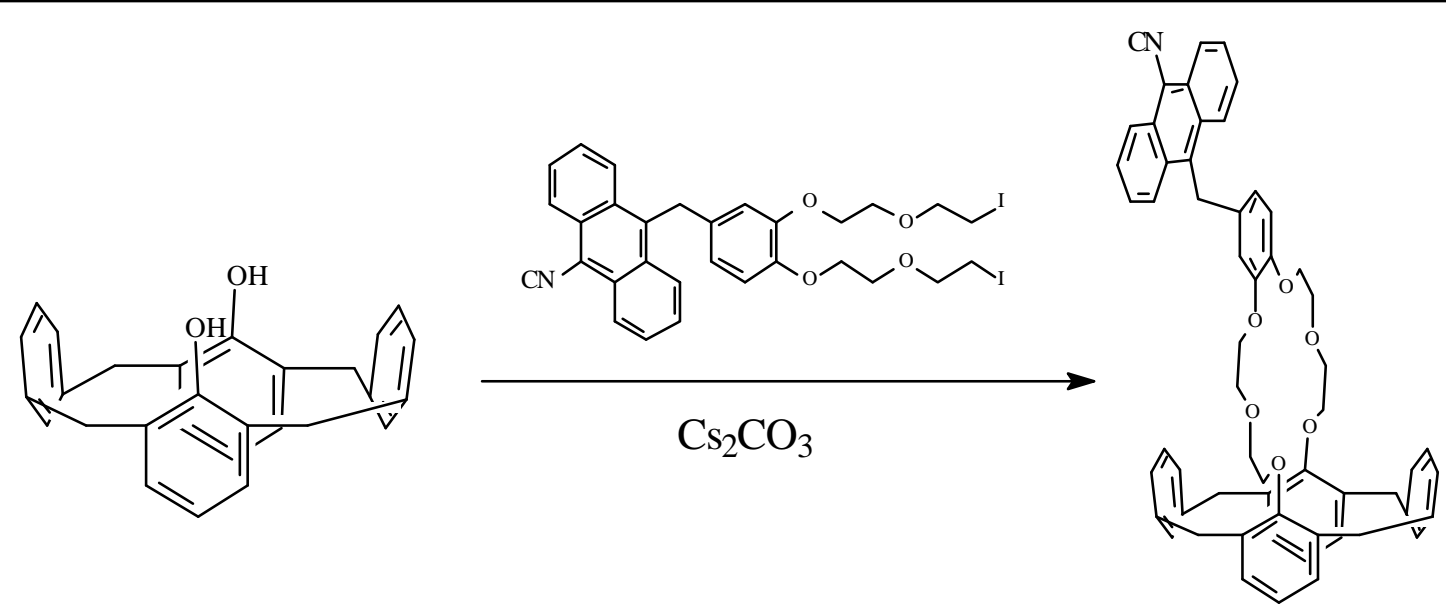

2

crown 1 exhibits not only enhanced cesium selectivity (both $\mathrm{K}_{\mathrm{Cs}} / \mathrm{K}_{\mathrm{K}}$ and $\mathrm{K}_{\mathrm{Cs}} / \mathrm{K}_{\mathrm{Rb}}$ ), but also show a fluorescence turn-on response significantly higher than any previously reported cesium sensor.

The emission behavior of (2) $\left(1 \times 10^{-6} \mathrm{M}\right)$ in $\mathrm{CH}_{2} \mathrm{Cl}_{2}: \mathrm{MeOH}(1: 1)$ in the presence of five different alkali metal cations is shown in the figure on the next page. The fluorescence quantum yield of (2) is enhanced 54.3 times when fully complexed with cesium at ca. $6 \times 10^{-6} \mathrm{M}$ of cesium.

This is the most dramatic emission response upon cesium

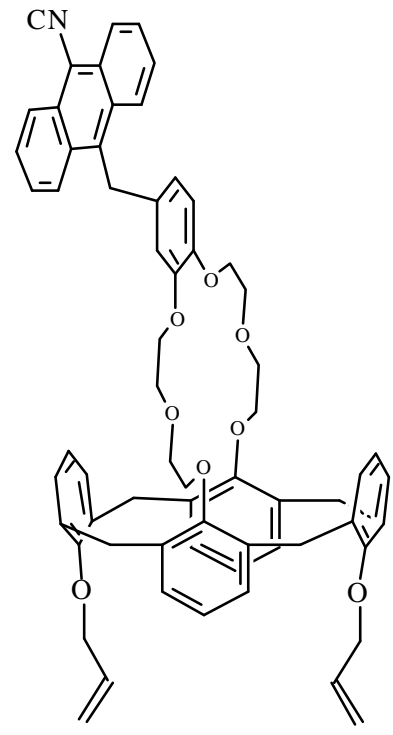
complexation of any cesium optical sensors reported to date. In comparison, the fluorescence of (3), 1,3-alternate dialkoxycalix[4]arene-(9-cyano-10-anthrylmethyl-benzo-crown-6, with the same fluorophore but based on a slightly different calix[4]arene platform, showed only 8.2 fold enhancement when fully complexed with cesium. $^{21}$ The dramatic fluorescence increase of $\mathbf{2}$ compared to 3 could be attributed to changes in the binding cavity of $\mathbf{2}$. The more sensitive response of $\mathbf{2}$ to cesium complexation suggests a stronger interaction between cesium cation and the ether oxygens of the benzo group in $\mathbf{2}$. Furthermore, the interaction of cesium ion with phenyl groups which reside on opposing sides of the crown ether cavity of $\mathbf{2}$ is expected to be weaker than that of cesium and 
phenolic ether ring in $\mathbf{3}$. This in turn can then result in a greater charge dispersion onto the oxygen of the crowns and subsequently stronger interaction between cesium and the benzo moiety. Although $\mathrm{Rb}^{+}$and $\mathrm{K}^{+}$complexation cause the fluorescence of 2 to increase (42.6 and 35.2 fold, respectively), their maximum responses occur at higher concentrations $\left(6 \times 10^{-5} \mathrm{M}\right.$ and $2 \times 10^{-3} \mathrm{M}$, respectively), suggesting that their association constants with 2 are much weaker than that of cesium. $\mathrm{Na}^{+}$and $\mathrm{Li}^{+}$show little effect on the fluorescence of $\mathbf{2}$, indicating a weak complexation of $\mathbf{2}$ by these ions. The 1:1 complexation constant were calculated from fluorescence intensity-metal ion concentration profile in the figure. The complexation constant of 2 with cesium $\left(4.0 \times 10^{6} \mathrm{M}^{-1}\right)$ is about one-third of the value obtained for $3\left(1.2 \times 10^{7} \mathrm{M}^{-1}\right)$. However, reflecting the increased selectivity of $\mathbf{3}$ for cesium, the complexation constants of $\mathbf{2}$ with $\mathrm{Rb}^{+}\left(3.02 \times 10^{5} \mathrm{M}^{-1}\right)$ and $\mathrm{K}^{+}\left(1.15 \times 10^{4} \mathrm{M}^{-1}\right)$ are significantly lower than those of $2\left(\mathrm{Rb}^{+}\right.$: $9.12 \times 10^{6} \mathrm{M}^{-1}$ and $\mathrm{K}^{+}: 3.2 \times 10^{5} \mathrm{M}^{-1}$ ), resulting in the selectivity ratios of $\mathrm{K}_{\mathrm{Cs}} / \mathrm{K}_{\mathrm{Rb}}=13.3$ and $\mathrm{K}_{\mathrm{C} s} / \mathrm{K}_{\mathrm{K}}=348$. These selectivities are $\sim 10$ fold higher than those calculated for 3 and other 1,3alternate dialkoxy-calix[4]-crown- 6 derivatives, consistent with those previously reported ${ }^{17}$ and emphasizing the importance of $\mathbf{2}$ as a cesium selective sensor in low $\mathrm{Cs}^{+}$concentrations. 


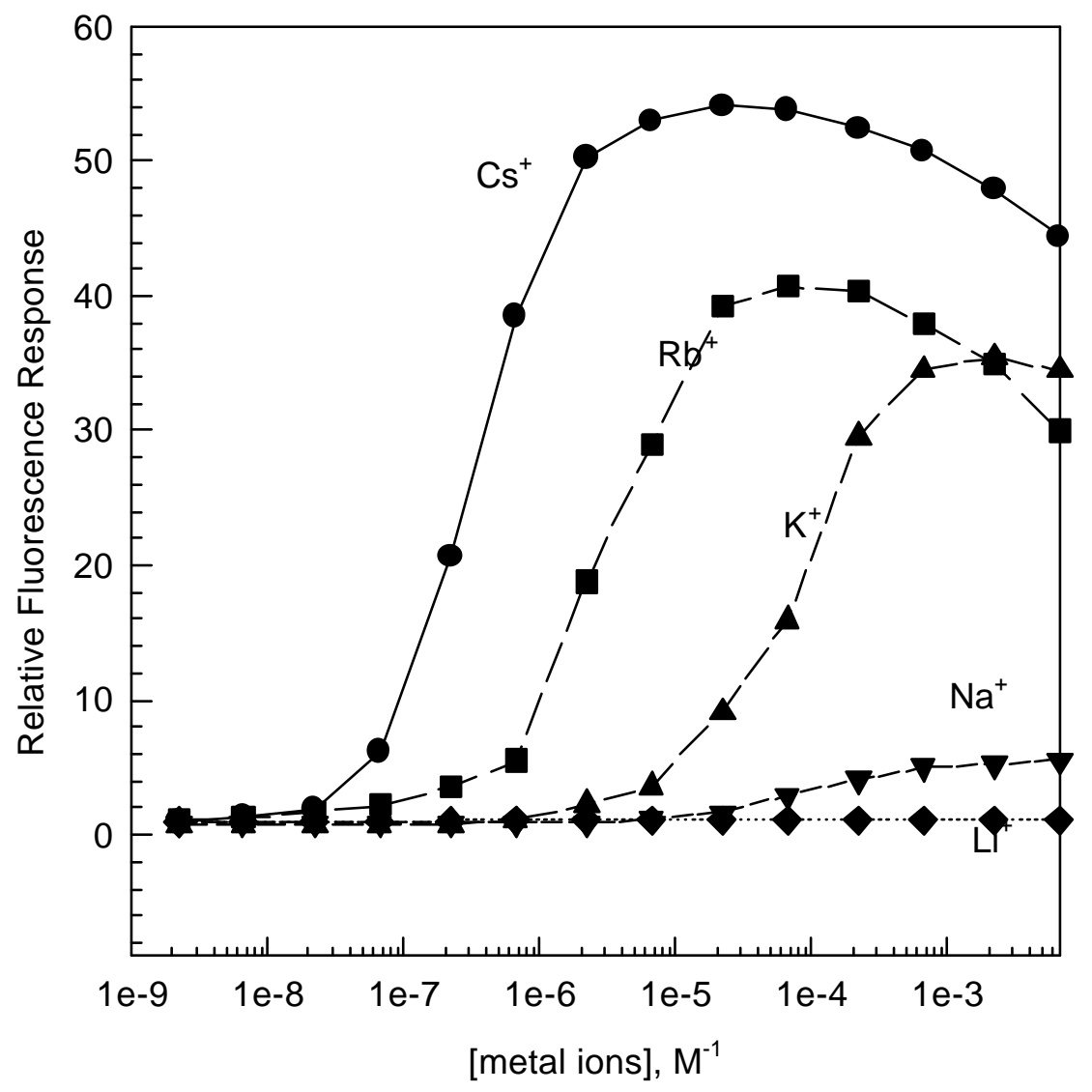

In order to evaluate the role of solvent on fluorescence response, we measured the fluorescence enhancement of $\mathbf{2}$ with cesium in $\mathrm{MeOH}$ and observed only a 6.5 fold enhancement. This could be due to the fact that PET quenching is more efficient in polar $\mathrm{MeOH}$ environment than in $\mathrm{CH}_{2} \mathrm{Cl}_{2}: \mathrm{MeOH}$ (1:1) mixture. In addition, the complexation constants of 2 with cesium and potassium are much smaller in $\mathrm{MeOH}$ than in the $1: 1 \mathrm{CH}_{2} \mathrm{Cl}_{2}: \mathrm{MeOH}$ mixture $\left(8.6 \times 10^{5} \mathrm{M}^{-1}\right.$ and 3.0x $10^{3} \mathrm{M}^{-1}$ respectively).

The high selectivity exhibited by calix[4]crown- 6 ethers towards the complexation of alkali metal ions has also been exploited to synthesize a supramolecular fluorescent recognition agent capable of detecting both potassium and cesium ions in solution by PET. ${ }^{28}$ The new probe serves as a dual optical sensor to signal the presence of (a) potassium ions (as low as $10^{-6} \mathrm{M}$ ) in the presence of cesium ion (at concentrations as high as $5 \times 10^{-4} \mathrm{M}$ ) under basic conditions and (b) cesium ions $\left(10^{-7} \mathrm{M}\right)$ in acidic media without any interference from potassium ion at concentrations as high as $10^{-5} \mathrm{M}$. The newly synthesized probe also behaves as an integrated logic gate combining an OR and a NAND gate for signal transduction. This is the first example of an integrated molecular logic device with feed back to the input of one logic element from the output of another. The new probe serves as a dual optical sensor to signal the presence of (a) potassium ions (as low as $10^{-6} \mathrm{M}$ ) in the presence of cesium ion (at concentrations as high as $5 \mathrm{x}$ $\left.10^{-4} \mathrm{M}\right)$ under basic conditions and (b) cesium ions $\left(10^{-7} \mathrm{M}\right)$ without any interference from 
potassium ion at concentrations as high as $10^{-5} \mathrm{M}$ in acidic media. This interesting application of our work was accepted for publication as a communication in the Journal of the American Chemical Society. A full paper describing the details has been submitted for publication.

Translation of Solution Results to an Organic Matrix. Traditionally, fluorescent potential-sensitive sensors for alkali ions that are based on neutral or ionizable ionophores incorporated into a liquid membrane using a poly(vinylchloride) (PVC) polymeric support. The origin of the widespread application of PVC can be understand from brief historical overview. To function properly, a liquid membrane has to possess good stability, be able to solubilize and hold the carrier, and have geometry optimal for the fast transport rates. Bulk and emulsion liquid membranes suffer from the instability and difficulty in recovering the receiving phase.

Supported liquid membranes offered an important advantage over bulk liquid membranes since they possess a small volume compared to the large interface. Supported liquid membranes usually suffer from degradation of the organic layer by different mechanisms; leaching of the carrier into the aqueous solution and emulsion formation are the most significant problems. A possible approach to overcome these difficulties is to combine the transport carrier with a plasticized polymeric membrane. The first polymer inclusion membranes (PIMs) were based on the poly(vinylchloride) (PVC) polymeric network. ${ }^{29}$ An attractive feature of the PIMs is that they possess greatly enhanced chemical and mechanical stability in comparison with other liquid membranes. ${ }^{30}$ PVC-based membranes have been successfully used in potentiometric sensors such as ion-selective electrodes or for the field-effect transistor, which do not require high fluxes of electroanalytically active species to function. ${ }^{31}$ These membranes did not find wide spread acceptance for cation separation because they exhibited low ionic permeability. ${ }^{29,32}$ It is commonly recognized that when neutral ionophores are used as sensing agents, high distribution of the ionic species into the membrane phase is highly desired in order to increase the optical response in the low concentration region. A search for the polymeric material that can promote distribution of the ions into PIM is of great importance. Later investigations demonstrated highly efficient transport of ionic species and excellent long-term stability by the cellulose triacetate (CTA) supported PIMs. ${ }^{33,34}$ In contrast with PVC membranes, such PIMs contain more solvent (typically as much as 70-80\%) due to the high affinity between NPOE and CTA. ${ }^{35}$ Gel-like CTA membranes absorb small amounts of water (about 2\%) that makes CTA not only an inert polymer support but also a crucial membrane component that promotes even hydration of the bulk membrane. In contast, water forms clusters in PVC membrane. ${ }^{36}$ The evenly hydrated CTA phase is especially important for the transport of ionic species.

Recently the feasibility of the transport of alkali metal ions, and cesium ion in particular, through PIMs containing CTA as support, an organic solvent, and calix[4]arene-crown-6 ligands as extractants $^{37}$ was demonstrated. It was of interest to test the applicability of the CTA PIMs 
for the purpose of developing a method of monitoring $\mathrm{Cs}^{+}$quantitatively in a complex aqueous media using calixcrown fluorescence agents incorporated into membrane. As previously noted, two different ligands containing cyanoanthracene fluorophore were demonstrated to selectively bind $\mathrm{Cs}^{+}$among other alkali metal ions. ${ }^{38}$ In an ideal situation, the intensity of the fluorescence signal of PIM-based sensor with fluorophore-ligands such as these would be directly proportional to the $\mathrm{Cs}^{+}$concentration in the aqueous solution. To meet this requirement, two problems have to be solved. First, an efficient uptake of the $\mathrm{Cs}^{+}$ions by membrane material should be achieved. Secondly, the probe fluorescence should be effectively quenched in the free, uncomplexed state and selectively enhanced by $\mathrm{Cs}^{+}$complexation. For a PIM with a given polymeric material (CTA in this study) and containing an extractant of a certain composition, both factors are considered to be primarily a function of a membrane solvent. The effect of the membrane solvent that serves not only as a solvent but also as a plasticizer in a polymeric membrane, on the facilitated transport of ionic species across PIMs has been studied. ${ }^{39}$ The requirements on the membrane solvent are demanding. To produce a stable membrane able to efficiently incorporate ionic species, the solvent should possess the following features:

- be immiscible with water, non-volatile, inert to the polymeric support;

- be capable of solubilizing the carrier and the complexing agent and it must minimize the partitioning of the carrier into the aqueous phase;

- have a suitable dielectric constant and suitable chemical properties to achieve a high value of the extraction constant;

- have high interfacial tension to diminish wettability of the polymeric support;

- solvate the backbone chain of the polymer.

In the survey experiments, the fluorescence response of the PIMs was measured using aqueous phase of (1) deionized water and (2) $0.07 \mathrm{M} \mathrm{CsClO}_{4}$ and then the ratio of the signal intensities was calculated and used for the purposes of a comparison of the performance of the different PIMs. When using PVC-octanol based PIMs, no change in the fluorescence was observed in changing from water only to the $\mathrm{CsClO}_{4}$ solution. Attention was given to the CTA system, and the effect of the membrane solvent on the change of the fluorescence response of the PIMs when aqueous phase of water was replaced by $0.07 \mathrm{M} \mathrm{CsClO}_{4}$ solution was studied with ligands 2 and 3. It was not possible to obtain PIMs with Isopar ${ }^{\circledR} \mathrm{L}$ without modifier, presumably due to low viscosity of this solvent and its inability to solvate CTA backbone. Both THP and DDM solvents formed PIMs of excellent mechanical stability. No change of the film was observed upon its contact with aqueous solution. Similar enhancement of the intensity of the fluorescence signal of PIMs containing THP and DDM without modifier was found upon 
exposure to the $\mathrm{Cs}^{+}$containing aqueous solution. This behavior can be attributed to the similar donor-acceptor functionality and polarity of both solvents. Comparison of the two ligands incorporated into PIMs with THP and DDM indicated that in both cases ligand $\mathbf{2}$ demonstrated superior performance. Fluorescence response of the PIM containing 2 was increased by about 2.3 times upon complexation of $\mathrm{Cs}^{+}$ions while only 1.3 times enhancement was observed with ligand 3. This observation is consistent with the previous results obtained in homogeneous solution ${ }^{38}$ and can be explained by structural and conformational properties of the ligand. $\mathrm{Cs}^{+}$ion is positioned inside the cavity of ligand $\mathbf{2}$ closer to the oxygen atoms adjacent to the benzo group of the crown ether moiety. This causes more significant withdraw of the electron density from the benzocrown moiety, the group responsible for quenching the cyanoanthracene group of 2 . The fact that PIM fluorescence response was enhanced upon exposure to the $\mathrm{Cs}^{+}$containing aqueous phase is very promising because it verifies that (1) $\mathrm{Cs}^{+}$ions are successfully extracted into PIM phase and (2) both THP and DDM solvents are compatible with fluorophore probe. The following modifiers were studied in combination with THP and Isopar $^{\circledR}$ L solvents: 1-decanol, 1H,H,5H-octafluoro-1-pentanol, 1-(1,2,3,3-tetrafluoroethoxy)-3-[4-(t-amyl)phenoxy]2-propanol, nonylphenol, and 4-sec-butyl-2-(alpha-methylbenzyl)phenol (BAMBP). PIMs containing ligand $\mathbf{3}$ were used in these experiments. The amount of modifier incorporated into membrane was $10 \mathrm{ww} \%$ of total solvent. Little or no enhancement of the fluorescence signal was observed using PIMs containing Isopar ${ }^{\circledR}$ L solvent, irrespective of the modifier employed. This result can be attributed to the low polarity of this kerosene-like solvent which is insufficient to provide for effective electron transfer between fluorophore and benzo group of the ligand as well as its ability solvate ionic species. When the THP membrane solvent was used, the modifier BAMBP was found to enhance the PIM fluorescence response most efficiently. A signal increase as large as 1.8 times was observed using PIMs containing ligand $\mathbf{3}$. In summarizing this survey, we concluded that PIMs containing either THP or DDM solvent with BAMBP modifier are the materials of choice for further experiments.

This preliminary investigation shows promise for the construction of a Cs sensor based on the CTA PIMs containing calixcrown fluorophores. Excellent mechanical and chemical stability of the CTA PIMs as well as biological and environmental integrity of the CTA material opens wide application range for such sensors. THP and DDM solvents in combination with BAMBP modifier are shown to be suitable for the effective cesium uptake into PIM phase and compatible with fluorophore probes. Sensitivity of the PIM toward $\mathrm{Cs}^{+}$ion can be increased by means of addition of $\mathrm{NaB}$ into the PIM phase. However, it is desired to enlarge the linear dynamic range of the quantitative PIM response to the $\mathrm{Cs}^{+}$ions for lower concentrations. For this purpose, the following strategies are proposed: (1) modification of the composition of the fluorophore probe to decrease its sensitivity to solvent environment; (2) test of the effect of the 
PIM polymeric support on the performance of the fluorophore; (3) search for the novel organic modifiers as well as lipophilic anions which can efficiently enhance cesium uptake and fluorescence response in the PIM phase.

\section{Relevance, Impact, and Technology Transfer}

Due to their relatively high abundance within the waste, and because of their approximate 30-year half lives, ${ }^{137} \mathrm{Cs}$ and ${ }^{90} \mathrm{Sr}$ are the most important radioactive fission products of Hanford Site tank wastes. Systems for disposing of retrieved Hanford Site tank wastes involve removal of the bulk of the ${ }^{137} \mathrm{Cs}$ and ${ }^{90} \mathrm{Sr}$ to obtain low level waste (LLW) that can be disposed of in near-surface facilities. For economic reasons involved in designing, constructing, and operating a cesium and strontium removal facility, it is particularly important to establish an accurate measure of the total inventory of radioactive and stable isotopes of cesium and strontium in the 177 underground tanks at the Hanford Site.

Recent determinations of the inventories of ${ }^{137} \mathrm{Cs}$ and ${ }^{90} \mathrm{Sr}$ radionuclides have been performed ${ }^{40}$ (Kupfur et al $1999 ;{ }^{41}$ Kirkbride et al $1999 ;{ }^{42}$ Hanlon 2000). For comparison purposes, it is convenient to consider separately the amounts of these two radionuclides in the Hanford double shell tanks (DSTs) and single shell tanks (SSTs). The inventories of cesium and strontium within double shell (DST) and single shell tanks (SST) are included in Tables 1 below.

The ratio of total cesium to ${ }^{137} \mathrm{Cs}$ is fairly constant for DST and SST wastes $\left(\mathrm{Cs} /{ }^{137} \mathrm{Cs}=\right.$ 2.5 and 2.9 for DST and SST wastes respectively, Table 1). In addition, on a tank by tank basis, the total cesium to ${ }^{137} \mathrm{Cs}$ ratio does not vary significantly from these values. The reason for the constancy in the stable-cesium to ${ }^{137} \mathrm{Cs}$ ratio is due to the constant relative fission yield of ${ }^{133} \mathrm{Cs}$ (stable cesium isotope) and ${ }^{137} \mathrm{Cs}$ (the primary radio-cesium product) and other cesium isotopes from ${ }^{235} \mathrm{U}$. In addition, extensive mixing and blending of wastes between tanks by repeated waste evaporation campaigns, resulted in the homogenization the soluble species within the waste (including the Cs isotopes). The concentration of total cesium is also fairly constant between the double shell and single shell tanks. The concentration of total Cs between double shell and single shell waste differs by only a factor of two; 9.0 E-5M (double shell) compared to 4.6E-5M (single shell) (Table 2). Slight variations in the total cesium and the isotopic ratio will occur due to ${ }^{133} \mathrm{Cs}$ (stable cesium) being introduced into the tanks as an impurity is the sodium hydroxide used in tank waste neutralization. Additionally, the ${ }^{137} \mathrm{Cs}$ content is slowly decreasing with time due to the decay of this radio-nuclide (half-life $=30 \mathrm{y}$ ).

Two double shell tanks exhibit a much lower $\mathrm{Cs} /{ }^{137} \mathrm{Cs}$ ratio than the average for all tanks. The double shell tanks, 241-AZ-101 and 241-AZ-102 have a Cs $/{ }^{137}$ Cs ratio of 1.78 and 1.72 respectively compared to 2.5 for all double shell tanks. The reason for this anomaly is that tanks 241-AZ-101 and 241-AZ-102 
Table 1. Cesium Inventories within Hanford Underground Tanks. From Best Basis Inventory [40,41,42].

\begin{tabular}{|c|c|c|c|c|}
\hline Tanks & \multicolumn{2}{|c|}{${ }^{137} \mathrm{Cs}$} & $\begin{array}{c}\text { Cs, total } \\
(\text { stable Cs }+ \\
137\end{array}$ & $\begin{array}{c}\text { Ratio, } \\
\text { total cesium/radio- } \\
\text { cesium }\end{array}$ \\
\hline $\begin{array}{c}\text { Double } \\
\text { Shell } \\
(28 \text { tanks })\end{array}$ & 32 & 367 & 907 & $\mathrm{KC} /{ }^{137} \mathrm{Cs}$ \\
\hline $\begin{array}{c}\text { Single Shell } \\
(149 \text { tanks })\end{array}$ & 24 & 271 & 783 & 2.5 \\
\hline $\begin{array}{c}\text { Total } \\
\text { (all tanks) }\end{array}$ & 55.4 & 637 & 1690 & 2.9 \\
\hline
\end{tabular}

received newly processed PUREX waste within the last 15 years. This waste was purposely not mixed with older, lower-activity waste. The ${ }^{137} \mathrm{Cs}$ content in these tanks is significantly higher than that in other tanks, explaining the low $\mathrm{Cs} /{ }^{137} \mathrm{Cs}$ ratio for these two waste tanks.

The Tanks Focus Area description of needs (SR01-2054-S) specifically mentions the need for a real-time sensor of $\mathrm{Sr}$ in a flowing liquid stream, and sensors based on fiber optics or other principles were mentioned. Interference from cesium, transuranics, and the bulk chemical constituents sodium, potassium, calcium, nitrate, nitrite, and hydroxide must be tolerated. Although it was not mentioned, aluminum in the chemical form of the tetrahydroxyaluminate anion must be tolerated as well. The array of sensors, allowing the interference to be specifically measured and accounted for, is the basis of our method. Optical sensors can be immediately adapted to highly alkaline solutions, but the desired sensitivity has not yet been achieved. Needs statement SR01-2054-S indicates that Sr-90 must be removed to a level of 4 to $10 \mathrm{nCi} / \mathrm{mL}$. The specific activity of Sr-90 is $143.5 \mathrm{Ci} / \mathrm{g}$ and $\mathrm{Sr}-90$ makes up about $1 \%$ of the total $\mathrm{Sr}$ in a typical waste tank. Therefore, the desired detection limits for $\operatorname{Sr}(\mathrm{II})$ as a chemical species is in the range 3 to $8 \times 10^{-8} \mathrm{M} / \mathrm{L}$. Based on our results in solution, this level should be readily achieved by an optical detection method for $\mathrm{Cs}^{+}$. There is every reason to believe that detection at this level for $\mathrm{Sr}^{2+}$ could be achieved as well.

In summary, the concentrations of total $\mathrm{Cs}^{+}$in $\mathrm{HLW}$ is of the order of magnitude $10^{-4} \mathrm{M}$ and the concentration of total $\mathrm{Sr}^{2+}$ is of the order of magnitude $10^{-3} \mathrm{M}$. In the call for proposals, the ability to detect $\mathrm{Sr}^{2+}$ at $4-10 \mathrm{nCi} / \mathrm{mL}$ is specifically mentioned. Converting from specific activity to concentration and multiplying by 100 to correct to total $\mathrm{Sr}$, the lower limit for 
detection is $3 \times 10^{-8} \mathrm{M}$. This should be readily detectable with the sensor elements under consideration.

\section{Project Productivity}

This project was productive as judged by the number of publications. We accomplished the objective of designing fluorescent turn-on ligands that are highly selective for cesium over the other alkali metal ions. However we were not able to realize a highly sensitive cesium selective sensor element in a solid matrix that could be attached to a fiber optic.

\section{Personnel Supported}

Partial support was provided to the following personnel:

PI

G. M. Brown (ORNL)

Co-PIs

R. Dabestani (ORNL)

P. V. Bonnesen (ORNL)

D. R. Walt (Tufts University)

Postdocs Hai-Feng Ji (ORNL)

C. L. Schauer (Tufts University)

\section{Peer Reviewed Publications}

A number of papers were accepted for publication in peer reviewed journals and two more have been submitted.

Hai-Feng Ji*, Hao Xu, Xiaohe Xu Reza Dabestani, and Gilbert M Brown, "Novel Fluorescent Probes for the Detection of Dual Mixed Alkali Ions that Function as an Integrated Logic Gate," Submitted for publication to J. Chem. Soc. Perkin Trans. 2.

Richard A. Sachleben, Jeffrey C. Bryan, Gilbert M. Brown, Reza Dabestani, Nancy L. Engle, Tamara J. Haverlock, Benjamin P. Hay, Hai-Feng Ji, Agathe Urvoas, and Bruce A. Moyer, "Rational Design of Cesium-Selective Ionophores and Chemosensors: Dihydrocalix[4]arene Crown-6 Ethers," Submitted for publication to Chemistry: A European Journal.

H-F.Ji, R. Dabestani, G. M. Brown and R. L. Hettich, "Synthesis and sensing behavior of cyanoanthracene modified 1,3-alternate calix[4]benzocrown-6: a new class of Cs-selectiveoptical sensors," J. Chem. Soc. Perkin Trans. 2, 2001, 585-591

H-F Ji, R.T. Dabestani, and G.M. Brown, “ Supramolecular Fluorescent Probe Activated by Protons to Detect Cesium and Potassium Ions Mimics the Function of a Logic Gate" J. Am. Chem. Soc, 2000, 122, 9306-9307. 
H-F Ji, R.T. Dabestani, G.M. Brown, and R.A. Sachleben, "A New Highly Selective Calix[4]Crown-6 Fluorescent Cesium Probe," J. Chem. Soc. Chemical Commun. 2000, 833-834.

H.-F. Ji, R. Dabestani, and G. M. Brown, "Optical Sensing of Cesium Using 1,3-Alternate Calix[4]-mono and di(anthrylmethyl)aza-crown-6," Photochem. Photobiol. 70, 1999 882-886.

H-F Ji,. G. M. Brown and R. Dabestani " Calix[4]arene-based cesium selective optical sensor" Chem. Comm. 609-610 (1999).

H-F.Ji, R. Dabestani, G. M. Brown and R. L. Hettich " Spacer length effect on the photoinduced electron transfer fluorescent probe for alkali metal ions" Photochem. Photobiol. 69, 513-516 (1999).

\section{Interactions}

The work stemming from this program was recognized for an award at Oak Ridge National Laboratory:

2000 UT Battelle ORNL Research Accomplishment Award for Significant Accomplishments in Previous Year for designing cesium-selective sensors based on novel supramolecular recognition agents.

Brown and Dabestani attended (and presented a poster) the first Environmental Management Science Program National Workshop in Chicago, July 1998, and presented both a poster and a platform presentation at the the second conference at Atlanta in 2000:

Reza Dabestani, Hai-Feng Ji, Peter V. Bonnesen, Tatiana G. Levitskaia and Gilbert M. Brown, and David W. Walt "Optical Sensing of Cesium Using Highly Selective Calix[4]arene-Crown-6 Derivatives," Second Environmental Management Science Program National Workshop,

Atlanta, GA, April 25-27, 2000

The PI was invited to make a presentation at Mercer University.

Gilbert M. Brown, Hai-Feng Ji, Reza Dabestani, Tatiana G. Levitskaia, Peter V. Bonnesen, Phillip F. Britt, Eric Finot and Thomas G. Thundat "Development of Cesium and Other Alkali Metal Ion Selective Sensors," Mercer University, Macon, GA, April 11, 2000.

Additional presentations resulted from this work were given at several National and Southeast Regional ACS Meetings.

Discussions of our results were held with Phil McGinnis of the Tanks Focus Area. 


\section{Patents}

No invention disclosures or patents resulted from this work.

\section{Future Work: Incorporation of Fluorescent Ligands into Matrices and Attachment to}

Fiber Optics. The success of this approach depends on the intrinsic binding affinity of the complexing agents for the ions of interest and the nature of the polymer microenvironment in which the complexing agent is immobilized. PIM based experimentsshould be continued to help define the requirements for good partitioning of the metal ions to the matrix and the dielectric constant requirements for good PET quenching/unquenching. Work should be done on ways that the calix-crowns can be immobilized on the surface of polymer beads. One method that this might be accomplished is in hydrophobic polymers by simple entrapment. Polymers such as polysiloxanes and polymethylmethacrylates can be polymerized on the bead surfaces. The calixcrowns will be dissolved in the organic prepolymer solution prior to polymerization., and polymerization will occur, entrapping the calix-crowns within the polymer matrix. The calixcrowns have no water solubility and will therefore remain within the polymer matrix. In order to facilitate metal ions to partition favorably into the polymer, it may be necessary to add modifiers. The sensor elements should also be tested with real tank waste or process waste samples from either the DOE's Hanford site or the Savannah River site.

\section{Literature Cited.}

${ }^{1}$ T. J. Haverlock, P. V. Bonnesen, R. A. Sachleben and B. A. Moyer, Radiochimica Acta, 1997, 76, 103;

${ }^{2}$ See for example Bocchi, C.; Careri, M.; Casnati, A.; Mori. G. Anal. Chem. 1995, 67, 42344238.

${ }^{3}$ Asfari, Z.; Bressot, C.; Vicens, J.; Hill, C.; Dozol, J.-F.; Rouquette, H.; Eymard, S.; Lamare, V.; Tournois, B. Anal. Chem. 1995, 67, 3133-3139.

4 (a) Czarnik, A.W. Acc. Chem. Res. 1994, 27, 302-308. (b) See contributions in Fluorescent Chemosensors for Ion and Molecular Recognition; Czarnik, A.W., Ed.; American Chemical Society: Washington, DC, 1993.; (c) de silva, Chem Rev,

${ }^{5}$ Bissell, R.A.; de Silva, A.P.; Gunaratne, H.Q.N.; Lynch, P.L.M.; Maguire, G.E.M.; McCoy, C.P.; Sandanayake, K.R.A.S. in Topics in Current Chemistry, Vol. 168; Springer-Verlag: Berlin, 1993, pp.223-264.

${ }^{6}$ Dessy, R. E. Anal. Chem. 1989, 61, 1079A-1094A

${ }^{7}$ Schultz, J. S. In Biosensors: Fundamentals and Applications; Turner, A. P. F., Karube, I., Wilson, G. S., Eds.; Oxford University Press: Oxford, 1987; pp 638-654.

${ }^{8}$ D.R. Walt, Accounts Chemical Research, 1998, 31, 267-8. 
9 "Monitoring Systems Based on 'Artificial Noses'", T.A. Dickinson, D.R. Walt, J. White, J. Kauer, Trends in Biotechnology, Vol 16, 6, 250-8, 1998.

${ }^{10}$ White, J., Kauer, J.S., Dickinson, T.A., Walt, D.R., Biological Cybernetics, 1998, 78, 245-251.

11 "Cross-reactive Chemical Sensor Arrays", K.J.Albert, N.S. Lewis, C.L. Schauer, G.A Sotzing, S.E. Stitzel, T.P. Vaid, and D.R. Walt, Chem Reviews, 100, 2595-2626. (2000).

12 "High-Speed Fluorescence Detection of Explosives-like Vapors" K.J. Albert and D.R. Walt, Anal. Chem. 72, 1947-1955 (2000)

13 “Bead-based Fiber-Optic Arrays", D.R. Walt, Science, 287, 451-452, 2000.

14 "High-throughput Screening of Unlabeled DNA Targets with Randomly-ordered Fiber-optic Gene Arrays", F.J. Steemers, J.A. Ferguson and D.R. Walt, Nature Biotechnology, 18, 91-94, 2000.

15 "A Fiber-optic Microarray Biosensor Using Aptamers as Receptors" M. Lee and D.R. Walt, Anal Biochem. 282, 142-146 (2000)

16 "Screening unlabeled DNA targets with randomly ordered fiber-optic gene arrays" F.J. Steemers, J.A. Ferguson, D.R. Walt, Nature Biotech, 18, 91-94 (2000)

17 "High Density Fiber-Optic DNA Random Microsphere Array" J. Ferguson, F. Steemers, D.R. Walt, Anal. Chem. 72, 5618-5624 (2000)

${ }^{18}$ K.L. Michael, L.C. Taylor, S.L. Schultz, D.R. Walt, Analytical Chemistry, Vol. 70, 7, 12421248, 1998.

${ }^{19}$ Paul Pantano and David R. Walt, Chemistry of Materials, Vol. 8, 2832-35 (1996).

${ }^{20}$ Dickinson, T. A.; White, J.; Kanar, J. S.; Walt, D. R.; Nature 1996, 382, 697-700.

21 "Convergent, Self-encoded Bead Sensor Arrays in the Design of an Artificial Nose", T. A.

Dickinson, K.L. Michael, J.S. Kauer, and D.R. Walt, Anal. Chem., 71, 2192-98, 1999.

${ }^{22}$ C. Hill, J.-F. Dozol, V. Lamare, H. Rouquette, S. Eymard and B. Tournois, J. Vicens, Z. Asfari and Bressot, J. Inclu. Phen. Mol. Recog. Chem. 1994, 19, 399-408.

${ }^{23}$ R. A. Sachleben, A. Urvoas, J. C. Bryan, T. J. Haverlock, B. P. Hay and B. A. Moyer, J. chem. Soc. Chem. Commun. 1999, 1751.

${ }^{24}$ C. Bocchi, M. Careri, A. Casnati, G. Mori, Anal. Chem., 1995, 67, 4234; H. Zeng, b.

Dureault, Talanta, 1998, 46, 1485; J. S. Kim, A. Ohki, R. Ueki, T. Ishizuka, T. Shimotashiro, S. Maeda, Talanta, 1999, 48, 705; C. Perez-Jimenez, L. Escriche, J. Casabo, Anal. Chim. Acta, 1998, 371, 155; R. J. W. Lugtenberg, Z. Brzozka, A. Casnati, R. Ungaro, J. F. J. Engbersen, D.

N. Reinhoudt, Analytica Chimica Acta, 1995, 310, 263.

${ }^{25}$ T. J. Haverlock, P. V. Bonnesen, R. A. Sachleben, and B. A. Moyer, J. Inclus. Phenom. Macrocyclic Chem., 2000, 36, 21-37.

${ }^{26}$ H.-F. Ji, G. M. Brown, R. Dabestani, J.Chem. Soc. Chem. Commun. 1999, 609; H.-F. Ji, , R. Dabestani, G. M. Brown, manuscript in preparation.

${ }^{27}$ A. Casnati, A. Pochini, R. Ungaro, F. Ugozzoli, F. Arnaud, S. Fanni, M. -J. Schwing, R. J. M. Egberink, F. de Jong, and D. N. Reinhoudt, J. Am. Chem. Soc. 1995, 117, 2767; F. Arnard-Neu, Z. Asfari, B. Souley, and J. Vicens, New J. Chem. 1996, 20, 453.

${ }^{28}$ A. P. de Silva and K. R. A. S. Sandanayake, J. Chem. Soc., Chem. Commun., 1989, 1183. 
${ }^{29}$ R. Block, O. Kedem, and D. Vofsi, Proc. Intern. Conf. Solv. Extr. Chem., Gothenburg 1966, North-Holland, Amsterdam, 1967 R. Block, A. Finkelstein, O. Kedem, and D. Vofsi, Ind. Eng. Chem., Process Des. Dev. 1967, 6, 231.

${ }^{30}$ A.M. Neplenbroek, D. Bargeman, and C.A. Smolders, J. Membr. Sci. 1992, 67, 149. L. Bromberg, G. Levin, and O. Kedem, J. Membr. Sci., 1992, 71, 41.

${ }^{31}$ M.L. Davies, C.J. Hamilton, S.M. Murphy, Biomaterials, 1992, 13, 971. A.S. Attiyat, G.D. Christian, C.V. Cason, and R.A. Bartsch, Anal. Chem., 1992, 4, 51. A.S. Attiyat, G.D. Christian, J.A. McDonough, B. Strzelbicka, Mi.J. Goo, Z.Y. Yu, and R.A. Bartsch, Anal. Lett, 1993, 26(7), 1413. C. Bocchi, M. Careri, A. Casnati, and G. Mori, Anal. Chem ., 1995, 67, 4234. A. Uhlig, E. Lindner, C. Teutloff, U. Schnakenberg, and R. Hintsche, Anal. Chem., 1997, 69, 4032. R.J.W. Lugtenberg, Z. Brzozka, A. Casnati, R. Ungaro, J.F.J. Engbersen, and D. N. Reinhoudt, Anal. Chim. Acta, 1995, 310, 263.

${ }^{32}$ H. Matsuoka, M. Aizawa, and S. Suzuki, J. Membr. Sci., 1980, 7, 11 M. Sugiura, J. Colloid Interface Sci., 1981, 81(2), 385. T. Hayashita, T. Fujimoto, Y. Morita, and R.A. Bartsch, Chem. Lett., 1994, 8, 2385.

${ }^{33}$ M. Sugiura and M. Kikkawa, Sep. Sci. Technol., 1987, 22(11), 2263. M. Sugiura, Sep. Sci. Technol., 1993, 28(7), 1453. M. Sugiura and H. Hirata, Sep. Sci. Technol., 1993, 28(10), 1933.

${ }^{34}$ T. Hayashita, M. Kumazawa, J.C. Lee, and R.A. Bartsch, Chem. Lett., 1995, 711. A.J. Schow, R.T. Peterson, and J.D. Lamb, J. Membr. Sci., 1996, 111(2), 291.

${ }^{35}$ T. Hayashita, M. Kumazawa, J.C. Lee, and R.A. Bartsch, Chem. Lett., 1995, 711.

${ }^{36}$ J.A. Riggs and B.D. Smith, J. Am. Chem. Soc., 1997, 119, 2765. M.-F. Paugam and J. Buffle, J. Membr. Sci., 1998, 147, 207. Q.T. Nguyen, E. Favre, Z.H. Ping, and J. Neel, J. Membr. Sci., 1996, 113, 137. Z. Li, X. Li, S. Petrovic, D.J. Harrison, Anal. Chem., 1996, 68, 1717. Z. Li, X. Li, M. Rothmaier, D.J. Harrison, Anal. Chem., 1996, 68, 1726.

${ }^{37}$ T.G. Levitskaia, D.M. Macdonald, J.D. Lamb, and B.A. Moyer, J. Phys. Chem. Chem. Phys. In press.

${ }^{38}$ Hai-Feng Ji, Reza Dabestani, Gilbert M. Brown and Richard A. Sachleben, J. Chem. Soc. Chemical Commun. 2000, 833-834..

${ }^{39}$ M. Sugiura, M. Kikkawa, and S. Urita, J. Membr. Sci., 1989, 42, 47. M. Sugiura, Sep. Sci. Technol., 1992, 27(2), 269.

${ }^{40}$ Kupfur, M.J., A.L Boldt, B.A. Higley, K. M. Hodgson, L. W. Shelton, B. C. Simpson, R. A. Watrous, M. D. LeClair, G. L. Borsheim, R. T. Winward, R. M. Orme, N. G. Colton, S. L. Lambert, D. E. Place, and W. W. Shulz. 1999. Standard Inventories of Chemicals and Radionuclides in Hanford Site Tank Wastes. HNF-SD-WM-TI-740, Rev 0B. Lockheed Martin Hanford Corporation, Richland, WA 99352.

${ }^{41}$ Kirkbride, R.A., G.K. Allen, R.M. Orme, R.S. Wittman (NHC), J.H. Baldwin, T.W. Crawford, J. Jo (LMHC), L.J. Fergestrom, T.M. Hohl, D.L. Penwell (Cogema). May 1999. Tank Waste Remediation System Operation and Utilization Plan. HNF-SD-WM-SP-012, Rev. 1, Vol. 1 and II. DOE-AC06-96RL13200. Numatic Hanford Corporation, Richland, Washington.

${ }^{42}$ Hanlon, B.M. May 2000. Waste Tank Summary Report for Month Ending March 31,2000. HNF-EP-0182-144. CH2M Hill Hanford Group, Inc., Richland, Washington. 